LETTERS

\title{
Extended colonic ulcerations in a patient with microscopic polyangiitis
}

\author{
C-N Tsai, C-M Chang, C-H Chuang, Y-T Jin, M-F Liu, C-R Wang
}

Ann Rheum Dis 2004;63:1521-1522. doi: 10.1136/ard.2003.018580

$M$ icroscopic polyangiitis is a necrotising vasculitis primarily affecting small vessels, with few or no immune deposits. Patients are characterised by positive antineutrophil cytoplasmic antibodies (ANCA), mainly perinuclear pattern. The spectrum of clinical manifestations is broad, including the kidney, musculoskeletal system, lung, gastrointestinal tract, skin, ear, nose, and throat, and neurological system. ${ }^{1}$ Although gastrointestinal disease is noted in half of the patients, the presentation is usually mild. ${ }^{2}$ Here, we report a patient with microscopic polyangiitis with initial presentation of extended colonic ulcerations and haemorrhage, characterised by a crypt abscess. To our knowledge, such a finding has not been reported previously.

\section{CASE REPORT}

A 69 year old man was admitted to hospital owing to leg oedema and body weight loss in the past 3 months. No systemic disease had previously been noted. He had a poor appetite and abdominal discomfort, but denied bowel habit changes, bloody or tarry stool.

On examination, vital signs were stable. Pale conjunctiva, mild abdominal tenderness, and pitting oedema over the legs were noted. Laboratory tests showed leucocytes $11.9 \times 10^{9} / 1$, haemoglobin $67 \mathrm{~g} / \mathrm{l}$, albumin $225 \mu \mathrm{mol} / \mathrm{l}$, C reactive protein $1157 \mathrm{mg} / \mathrm{l}$, and erythrocyte sedimentation rate more than $150 \mathrm{~mm} / \mathrm{lst} \mathrm{h}$. Daily urinary protein loss was $0.7 \mathrm{~g}$. Stool examination showed positive occult blood. However, the results of panendoscopy and lower gastrointestinal investigations were negative.

Intermittent high fever was noted several days after admission. No infectious focus was identified by repeated blood and stool cultures. Abdominal computed tomography disclosed mild inflammation over the mesentery. Colonoscopy showed markedly swelling mucosa with haemorrhage and ulcers from rectum to the cecum (fig lA). A pathology examination reported inflammatory infiltrates in the lamina propria, destruction of the mucosal gland, and a crypt abscess (fig 1B). Ulcerative colitis was diagnosed, and mesalazine and prednisolone $30 \mathrm{mg}$ every day were prescribed.

Sudden onset of haemoptysis occurred 1 week later and pulmonary haemorrhage was diagnosed. Intravenous methylprednisolone $20 \mathrm{mg}$ every 8 hours was given, and the haemoptysis disappeared 1 week later. Repeated urinary analysis showed a daily protein loss of $4 \mathrm{~g}$. An autoantibody examination showed negative antinuclear antibodies and antiglomerular basement membrane antibody. ANCA were positive (perinuclear pattern, $\times 320$ ), and further analysis showed positive antimyeloperoxidase $103 \mathrm{U} / \mathrm{ml}$ (normal range $<20 \mathrm{U} / \mathrm{ml}$ ). A renal biopsy showed glomerular necrosis, cellular crescent, interlobular arteritis, diffuse tubular atrophy, and few immune deposits. The final diagnosis was microscopic polyangiitis with a rare presentation of extended colonic ulcerations. Pulse intravenous cyclophosphamide
$700 \mathrm{mg}$ was given and steroid was gradually tapered. Proteinuria, hypoalbuminaemia, anaemia and inflammatory measures improved with treatment. He was discharged and received monthly pulse cyclophosphamide treatment thereafter. Neither abdominal pain nor diarrhoea was noted during follow up at the outpatient clinic.
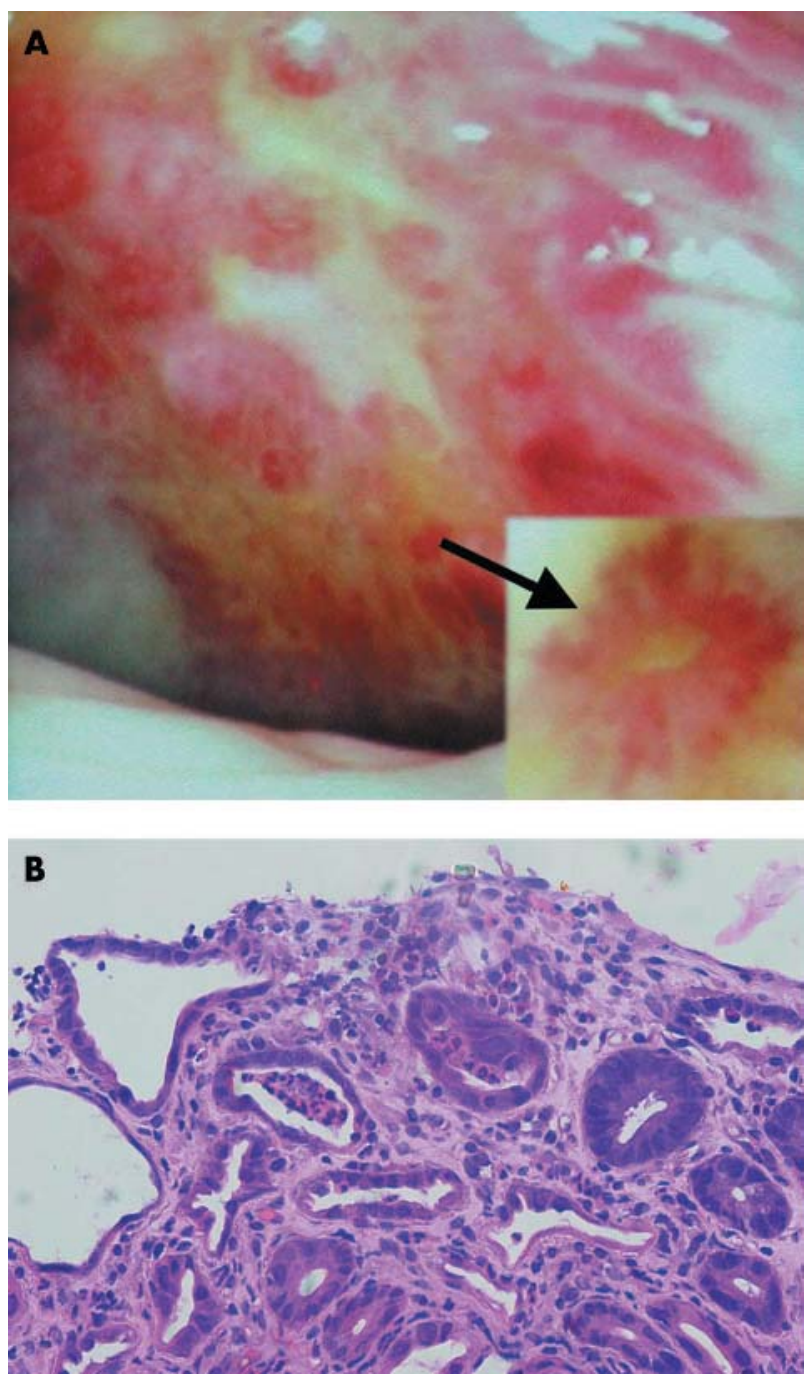

Figure 1 (A) The mucosa of the sigmoid colon was hyperaemic, oedematous, and markedly uneven, with multiple ulcers and haemorrhage. The ulcers were irregular in shape and varied in size. Some cotton wool-like vascular pattern (arrow) was also noted in the surrounding mucosa. (B) Colonic biopsy specimen showing inflammatory cell infiltrating the lamina propria, destruction of the mucosal gland, and marked crypt abscess (haematoxylin and eosin, $\times 200$ ) 


\section{DISCUSSION}

In microscopic polyangiitis, necrotising glomerulonephritis is the most common abnormality and pulmonary capillaritis often occurs. Perinuclear ANCA are present in more than $60 \%$ of patients, and antimyeloperoxidase antibody is closely allied. ${ }^{1}$ Gastrointestinal involvement is usually mild and there is no report of extended colonic ulcerations and haemorrhage. ${ }^{2}$ In addition, colonic biopsy disclosed crypt abscess, which can be found in ulcerative colitis, infectious colitis, radiation induced colitis, and graft versus host disease. $^{3-5}$ However, such a finding has not been reported previously in patients with microscopic polyangiitis. Ulcerative colitis was diagnosed initially according to the colonoscopic and pathological findings. Pulmonary vasculitis is very rare in patients with inflammatory bowel diseases. ${ }^{6}$ Renal disease with necrotising glomerulonephritis is not commonly seen in patients with ulcerative colitis. ${ }^{7}$ In addition, antimyeloperoxidase antibody is usually not detected in such patients. ${ }^{8}$ The clinical course of this patient who had lung and renal manifestations did not favour a diagnosis of ulcerative colitis. The final diagnosis was microscopic polyangiitis with gastrointestinal involvement.

Extended colonic ulcerations with haemorrhage have not been reported previously in patients with microscopic polyangiitis. Vasculitis should be considered for differential diagnoses of colonic ulcerations, especially when the presentation is atypical, to avoid delay of prompt treatment.

\section{Authors' affiliations}

C-N Tsai, M-F Liu, C-R Wang, Section of Rheumatology, Department of Internal Medicine, College of Medicine, National Cheng Kung University, Tainan, Taiwan
C-M Chang, Section of Geriatrics, Department of Internal Medicine, College of Medicine, National Cheng Kung University, Tainan, Taiwan C-H Chuang, Section of Gastroenterology, Department of Internal Medicine, College of Medicine, National Cheng Kung University, Tainan, Taiwan

Y-T Jin, Department of Pathology, College of Medicine, National ChengKung University, Tainan, Taiwan

Correspondence to: Dr C-R Wang, Section of Rheumatology and Section of Allergy and Immunology, Department of Internal Medicine, College of Medicine, National Cheng Kung University, No 1, University Road, Tainan, Taiwan; wangcr@mail.ncku.edu.tw

Accepted 10 March 2004

\section{REFERENCES}

1 Jennette JC, Falk RJ. Small-vessel vasculitis. N Engl J Med 1997:337:1512-23.

2 Guillevin L, Durand-Gasselin B, Cevallos R, Gayraud M, Lhote F, Callard P, et al. Microscopic polyangiitis: clinical and laboratory findings in 85 patients. Arthritis Rheum 1999:42:421-30.

3 Boyd JF. Pathology of the alimentary tract in Salmonella typhimurium food poisoning. Gut 1985;26:935-44.

4 Northway MG, Scobey MW, Geisinger KR. Radiation proctitis in the rat. Sequential changes and effects of anti-inflammatory agents. Cancer 1988:62:1962-9

5 Epstein RJ, McDonald GB, Sale GE, Shulman HM, Thomas ED. The diagnostic accuracy of the rectal biopsy in acute graft-versus-host disease: a prospective study of thirteen patients. Gastroenterology 1980;78:764-71.

6 Storch I, Sachar D, Katz S. Pulmonary manifestations of inflammatory bowel disease. Inflamm Bowel Dis 2003;9:104-15.

7 Wilcox GM, Aretz HT, Roy MA, Roche JK. Glomerulonephritis associated with inflammatory bowel disease. Gastroenterology 1990;98:786-91.

8 Abad E, Tural C, Mirapeix E, Cuxart A. Relationship between ANCA and clinical activity in inflammatory bowel disease: variation in prevalence of ANCA and evidence of heterogeneity. J Autoimmun 1997; 10:175-80.

\section{Severe digital ischaemia treated with phosphodiesterase inhibitors}

\section{R Kumana, G T Y Cheung, C S Lau}

$\mathrm{P}$ ulmonary hypertension is associated with autoimmune diseases, giving rise to digital ischaemia, including Raynaud's phenomenon (RP). As sildenafil, a phosphodiesterase-5 (PDE-5) inhibitor, relieves the pulmonary hypertension, ${ }^{1}$ we suggested that it might also benefit digital ischaemia and RP symptoms. This report describes the impact of oral sildenafil (Viagra, donated by Pfizer HK) on three women with autoimmune disease and progressively severe digital ischaemia, despite treatment with a variety of drugs, including intravenous iloprost (fig 1). All patients gave written informed consent to try this off-label treatment.

\section{CASE REPORTS}

A 42 year old woman with dermatomyositis "sine myositis" and thyrotoxicosis (case 1) taking prednisolone, hydroxychloroquine, and carbimazole, experienced regression of troublesome RP and ischaemic digital ulceration after receiving diltiazem SR $200 \mathrm{mg} /$ day and thrice monthly iloprost infusions. Ten months later, antituberculosis chemotherapy was started and the steroid dosage reduced, after she developed a febrile illness with cough, pleuropericardial effusions, and sputum culture positive for tuberculosis (TB). Digital gangrene supervened in both hands and both feet despite daily intravenous iloprost infusions for 2 weeks.
A day after starting sildenafil $50 \mathrm{mg}$ three times a day her digital circulation and pain improved markedly; facial flushing was the only adverse reaction. In view of the slightly deteriorating digital ischaemia and experimental evidence, ${ }^{23}$ we inferred that rifampicin treatment was inducing the metabolism of sildenafil. Its dosage was therefore doubled. Symptomatic improvement continued and ischaemic tissues became demarcated. However, 26 days after starting sildenafil she succumbed to uncontrolled pulmonary TB.

A 28 year old woman with scleroderma/lupus (case 2) who had been receiving diltiazem, domperidone, omeprazole, and penicillamine for about 4 years presented with progressive breathlessness. Computed tomography of the thorax suggested fibrosing alveolitis; prednisolone and azathioprine were started. Thereafter, she incurred occasional chest infections, other complications, and features of autoimmune diseases. She then developed persistent high grade fever, chills, rigors, night sweats, and increasingly severe digital arthralgia, vasculitis, and ischaemia. A polymerase chain reaction (PCR) of blood disclosed disseminated TB. Despite resolution of the sepsis after anti-TB chemotherapy, she developed progressive ischaemia and impending gangrene of her fingers, toes, and feet, despite regular infusions of iloprost for 2 weeks. One day after starting sildenafil $50 \mathrm{mg}$ 

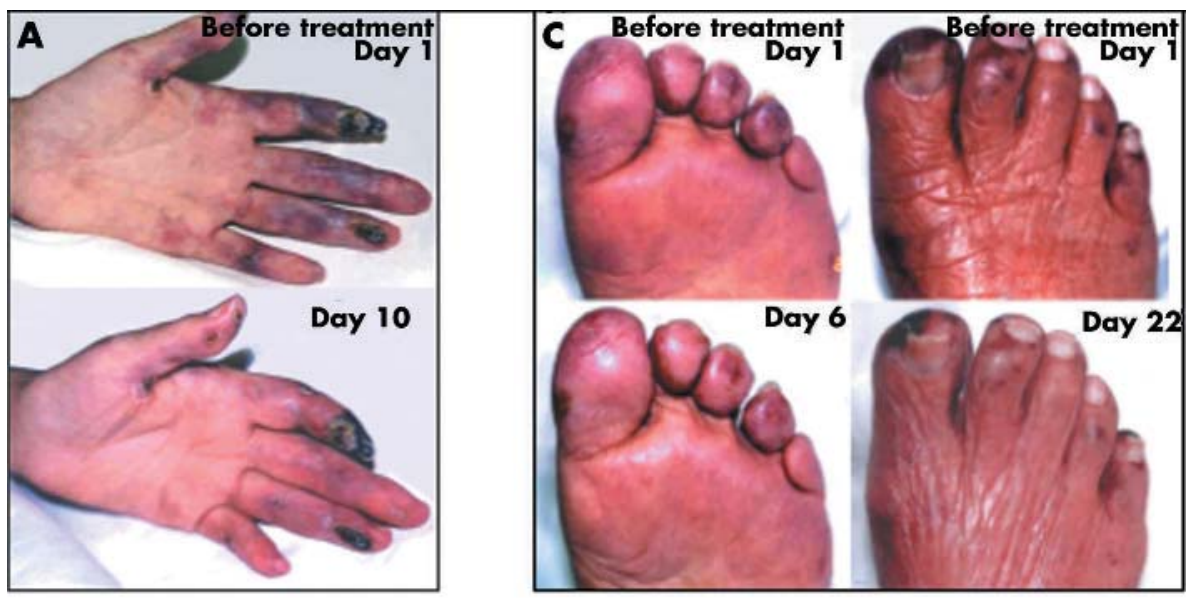

Figure $1(A),(B)$, and $(C)$ refer to cases 1, 2, and 3, respectively. In all three cases, ischaemia of viable tissues resolved after treatment with sildenafil (and tadalafil in case 2). (B) shows that increased finger extension became possible after treatment.

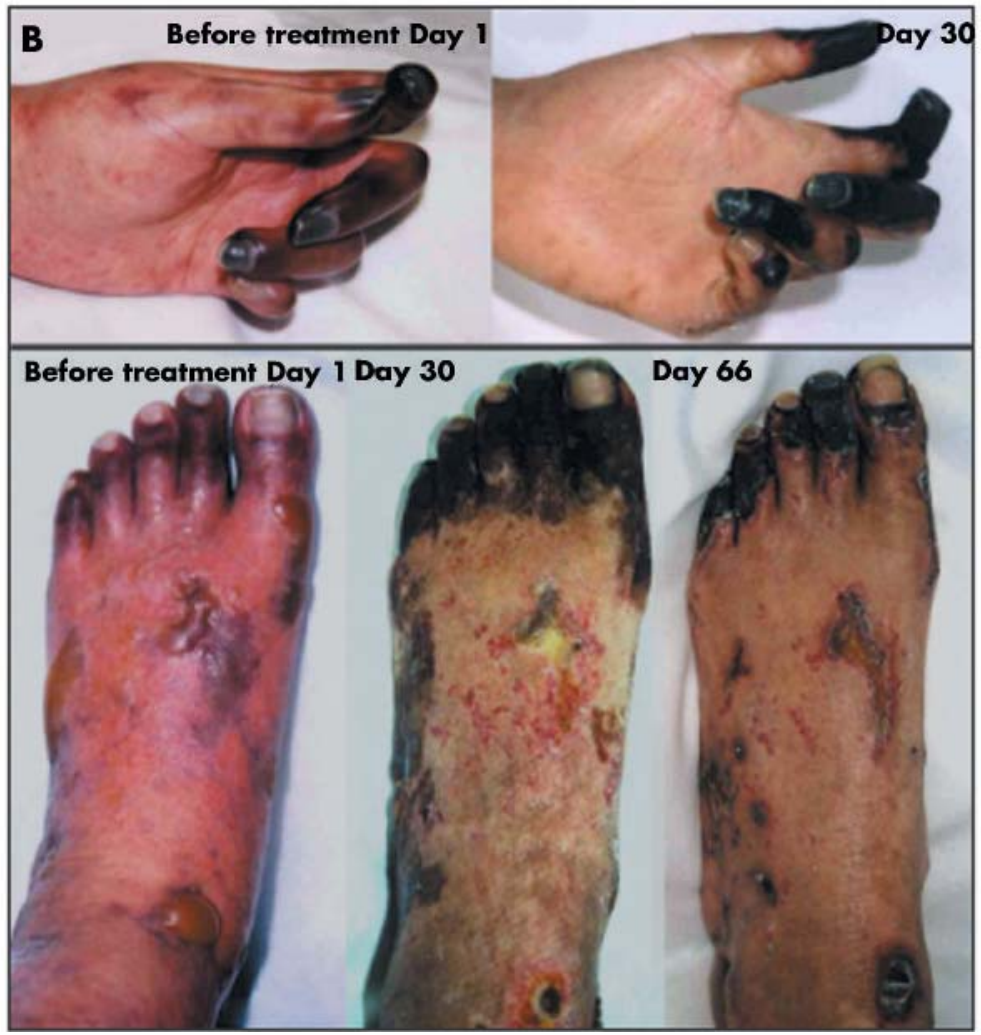

three times a day, all four extremities showed marked symptomatic improvement, becoming warm, less painful, and less discoloured. Her digital vasculitis resolved; weeks later necrotic zones became demarcated and autoamputated. Owing to resurgence of active lupus, her prednisolone dosage was increased; her haematological/serological abnormalities regressed. After 48 days of sildenafil treatment, tadalafil (Cialis) $10 \mathrm{mg}$ once daily was substituted for 78 more days, without any adverse reaction. Currently, the patient remains well and can stand.

A 76 year old woman with prior hypertension and ischaemic heart disease (case 3) presented with erythematous facial and finger rashes, myalgia, finger and toe ischaemic lesions, and proximal muscle weakness. Dermatomyositis and a disseminated malignancy were diagnosed. After mutually agreeing to stop further investigation, prednisolone treatment was started. Her digital ischaemia responded poorly to diltiazem SR and any improvement during iloprost infusions disappeared when they stopped. After 12 days and despite her past medical history, sildenafil treatment was cautiously started, with immediate reduction in peripheral pain and ischaemia and healing of toe ulcers. Although well tolerated, sildenafil was discontinued after 3 weeks, as the patient required treatment with nitrates.

\section{DISCUSSION}

All three patients had immediate, subjective and objective improvements after initiating sildenafil, which was entirely consistent with Lichtenstein's observations, except that our patients were very severely afflicted. ${ }^{4}$ In two patients, worsening RP and digital ischaemia appeared during active $\mathrm{TB}$, consistent with the effects of sepsis. ${ }^{5}$ Rifampicin, a powerful inducer of relevant P450 enzymes (apt to enhance sildenafil elimination ${ }^{2}$ ), appeared to affect their management. These 
observations merit a randomised controlled trial to investigate the treatment of disabling RP with oral PDE-5 inhibitors.

\author{
Authors' affiliations \\ C R Kumana, G T Y Cheung, C S Lau, Department of Medicine, The \\ University of Hong Kong, 8/F Administration Block, Queen Mary \\ Hospital, Hong Kong \\ Correspondence to: Professor C S Lau; cslau@hkucc.hku.hk
}

Accepted 29 December 2003

\section{REFERENCES}

1 Michelakis ED. The role of the NO axis and its therapeutic implications in pulmonary arterial hypertension. Heart Fail Rev 2003;8:5-21.

2 Thummel KE, Wilkinson GR. In vitro and in vivo drug interactions involving human CYP3A. Annu Rev Pharmacol Toxicol 1998;38:389-430.

3 Warrington JS, Shader RI, Von Moltke LL, Greenblatt DJ. In vitro biotransformation of sildenafil (Viagra): identification of human cytochromes and potential drug interactions. Drug Metab Dispos 2000;28:392-7.

4 Lichtenstein JR. Use of sildenafil citrate in Raynaud's phenomenon: comment on the article by Thompson et al. Arthritis Rheum 2003;48:282-83.

5 Haj MA, Robbie LA, Adey GD, Bennett B. Inhibitors of plasminogen activator in neutrophils and mononuclear cells from septic patients. Thromb Haemost 1995; 74:1528-32.

\title{
Hereditary Clq deficiency and secondary Sjögren's syndrome
}

\author{
E P A H Hoppenreijs, P J van Dijken, P J Kabel, J M Th Draaisma
}

Ann Rheum Dis 2004;63:1524-1525. doi: 10.1136/ard.2003.016592

$\Lambda$ 13 year old Turkish boy with a known Clq deficiency and SLE-like disease developed recurrent parotitis. Investigations confirmed a secondary Sjögren's syndrome (SS). As far as we know, the association between Clq deficiency and SS has not been described before. The potential role of $\mathrm{Clq}$ in the pathogenesis of SS and systemic lupus erythematosus (SLE) might stimulate further research in understanding the pathogenesis of these and other autoimmune diseases. Screening patients with SS for complement deficiencies, including $\mathrm{Clq}$ deficiency, seems indicated.

Deficiency of the complement component $\mathrm{Clq}$ is a rare genetic disorder with susceptibility to recurrent infections with polysaccharide encapsulated micro-organisms and a high prevalence of autoimmune phenomena, most often SLE.

\section{CASE REPORT}

At the age of 4 years a boy of consanguineous Turkish descent had meningitis of unknown origin. At the age of 8 years he presented with meningococcal sepsis and meningitis. In the late convalescent phase of this infection he developed arthritis of his right elbow and pericarditis. At the age of 10 years he was admitted owing to lobular pneumonia. Immunological studies at that time demonstrated no functional or antigenic activity of Clq based on a homozygous Glu-86 stop mutation in the ClqA gene exon 2. Both parents and a sibling sister were found to be asymptomatic heterozygous carriers. His sibling brother, who also developed SLE-like symptoms, was homozygous for this mutation.

At the age of 13 years the patient developed recurrent arthritis of the ankle and elbow. Two years later he presented with six episodes of alternate right and left parotitis. There were no complaints of dry mouth or dry eyes. Ultrasonography of the parotid gland during an episode of parotitis disclosed diffuse swelling. Salivary scintigraphy showed delayed tracer uptake. Ocular examination showed some corneal erosion, a normal Schirmer test, and a tear break up time of 10 seconds. A salivary gland biopsy showed lymphocytic sialoadenitis with a focus score of 4 and a percentage of plasma cells containing IgA of $9 \%$, consistent with SS. Microscopic haematuria and proteinuria were not present. Immunological studies showed positive antinuclear antibodies (ANA), RNP antibodies, anti-Sm antibodies, antiSSA antibodies, and a positive rheumatoid factor (RF). AntiSSB antibodies and anti-dsDNA antibodies were not detected. A direct Coombs test and a serological test for syphilis were negative. Serum immunoglobulins were slightly raised. C3 and C4 were normal.

\section{DISCUSSION}

In our patient a homozygous point mutation in the ClqA gene was demonstrated that has earlier been described in five families from the Slovak republic and Turkey. ${ }^{1}$ With arthritis, a positive ANA test, and anti-Sm antibodies our patient has an SLE-like disease. ${ }^{2}$ Patients with SLE commonly have sicca symptoms, which may be related to the concomitant occurrence of SS. ${ }^{3}$ Secondary SS, in which the disease coexists with an autoimmune disease, is defined by the presence of either ocular or oral symptoms and two of four objective classification criteria. ${ }^{4}$ Our patient with recurrent swollen salivary glands, autoantibodies to ANA, RF, and SSA, a salivary scintigraphy showing delayed uptake, and biopsy findings consistent with SS, meets the full criteria for secondary SS.

These observations suggest that absence or abnormal function of Clq leads to susceptibility for SLE and SS. This may be due to ineffective immune complex clearance that causes tissue injury, exposes autoantigens, and stimulates an autoantibody response. ${ }^{5}$ In this respect it is significant that our patient had late onset reactive arthritis and pericarditis related to his meningococcal disease, which is also mediated by immune complexes. ${ }^{6}$ Other data suggest a defective clearance of apoptotic cells, which promotes accumulation of nucleosomes (suggested antigens in SLE), which in turn drives an autoimmune response. ${ }^{7}$

In conclusion we report a patient with Clq deficiency, SLElike disease, and secondary SS. This is the first time that an association between Clq deficiency and SS has been reported. It suggests a role for $\mathrm{Clq}$ in the pathogenesis of autoimmune diseases, possibly due to ineffective immune complex clearing or defective apoptosis, and warrants further research.

Screening of patients with Clq deficiency for SS, but especially screening of patients with SS for complement deficiencies, including Clq deficiency, seems indicated.

\section{Authors' affiliations}

E P A H Hoppenreijs, Department of Paediatrics, University Medical Centre Utrecht, The Netherlands 
P J van Dijken, Department of Paediatrics, St Elisabeth Hospital Tilburg, The Netherlands

P J Kabel, Department of Medical Microbiology, St Elisabeth Hospital Tilburg, The Netherlands

J M Th Draaisma, Department of Paediatrics, University Medical Centre Nijmegen, The Netherlands

Correspondence to: Dr E P A H Hoppenreijs, Department of Paediatrics, University Medical Centre Utrecht, Wilhelmina Kinderziekenhuis, PO Box 85090, 3508 AB Utrecht, the Netherlands; e.p.a.h.hoppenreij@@wkz.azu.nl

Accepted 22 December 2003

\section{REFERENCES}

1 Petry F, Berkel Al, Loos M. Multiple identification of a particular type of hereditary $\mathrm{Clq}$ deficiency in the Turkish population: review of the cases and additional genetic and functional analysis. Hum Genet 1997; 100:51-6.

2 Tan EM, Cohen AS, Fries JF, Masi AT, McShane DJ, Rothfield NF, et al. The 1982 revised criteria for the classification of systemic lupus erythematosus. Arthritis Rheum 1982;25:1271-7.

3 Gilboe IM, Kvien TK, Uhlig T, Husby G. Sicca symptoms and secondary Sjögren's syndrome in systemic lupus erythematosus: comparison with rheumatoid arthritis and correlation with disease variables. Ann Rheum Dis $2001 ; 60: 1103-9$

4 Viali C, Bombardieri S, Jonsson R, Moutsopoulos HM, Alexander EL, Carsons SE, et al. European Study Group on Classification Criteria for Siögren's Syndrome. Ann Rheum Dis 2002;61: 554-8.

5 Walport MJ, Davies KA, Botto M. Clq and systemic lupus erythematosus. Immunobiology 1998;199:265-85.

6 Finkelstein Y, Adler Y, Nussinovitch M, Varsano I, Amir J. A new classification for pericarditis associated with meningococcal infection. Eur J Pediatr 1997; 156:585-8.

7 Bach JF, Koutouzov S. Immunology: new clues to systemic lupus. Lancet 1997;350(suppl III): 11.

\section{Acute pneumonitis starting 2 hours after intramuscular gold administration in a patient with rheumatoid arthritis}

\section{A Hafejee, M J Burke}

G old salts have been used for the treatment of rheumatoid arthritis (RA) for over 50 years. ${ }^{1}$ Their use is limited by the incidence of adverse reactions, including pneumonitis. Most case reports describe pneumonitis developing after a cumulative dose of several hundred milligrams. ${ }^{2}$ Only four cases of lung disease have been reported with a cumulative dose of $<100 \mathrm{mg}^{3}$

Here we report a case of gold pneumonitis, starting only 2 hours after the first maintenance dose of $20 \mathrm{mg}$ was administered.

\section{CASE REPORT}

A 54 year old woman with RA had been followed up since 1984, her arthritis being well controlled with chloroquine. In 1997 her disease had flared up, and alternative disease modifying drugs were introduced-sulfasalazine, then methotrexate (both of were stopped because of adverse side effects), and finally, leflunomide. The last of these caused leucopenia and hypertension (controlled with bendrofluazide and ramipril) and hence was discontinued. Subsequently, her disease became more active again with prolonged joint stiffness, hand synovitis, and erythrocyte sedimentation rate (ESR) $102 \mathrm{~mm} / \mathrm{lst} \mathrm{h}$.

Treatment was started with gold injections, with a test dose of $10 \mathrm{mg}$ (no adverse effects noted), followed a week later by a dose of $20 \mathrm{mg}$. About 2 hours afterwards she complained of dizziness, nausea, then she developed a cough and breathlessness. She was admitted to hospital later that day. On examination she was apyrexial, tachypnoeic, cyanosed (oxygen saturation $79 \%$ on air), pulse 110/minute, blood pressure $80 / 46$, heart sounds normal, and had no signs of heart failure.

Investigations showed haemoglobin of $103 \mathrm{~g} / \mathrm{l}$ with normal white cell and platelet counts. C reactive protein was $115 \mathrm{mg} / \mathrm{l}$ and troponin-I (a marker for myocardial infarction) was normal at $0.1 \mu \mathrm{g} / \mathrm{l}$. Arterial blood gases on air showed a type 1 respiratory failure pattern. A chest $x$ ray examination showed bilateral lower zone alveolar shadowing. An echocardiogram showed a normal ejection fraction.
After high dose oxygen treatment, intravenous hydrocorti-

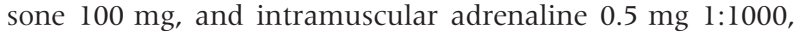
some improvement was seen clinically, oxygen saturation rising to $90 \%$ and blood pressure to $116 / 69$. She was admitted to the high dependency unit and treatment started with pulse methylprednisolone $\mathrm{lg}$ daily, nasal continuous positive airway pressure ventilation, and required parenteral nutrition. On the day after her admission, she developed a generalised macular rash. Over the next 7 days her clinical condition improved (serial chest $x$ ray examinations over this period showed clearing of the previous alveolar shadowing), and her treatment was changed to a reducing regimen of oral steroids. She was discharged, continuing frumil once daily and prednisolone $5 \mathrm{mg}$ daily. Her arthritis was inactive and blood pressure 110/70. The ESR was $22 \mathrm{~mm} / \mathrm{lst} \mathrm{h}$.

During her admission, it was considered that owing to the severity of her illness she was not fit enough to have other investigations-for example, computed tomography chest scan, bronchoalveolar lavage, and pulmonary function tests.

The gold was discontinued and her arthritis remains in remission.

\section{DISCUSSION}

Gold pneumonitis is a potentially fatal complication of gold salt treatment. This case illustrates two important points in management:

- Some of the early symptoms could have been confused with a nitritoid reaction. Indeed, hypertensive patients with RA who are taking angiotensin converting enzyme inhibitors (in this case ramipril) show a higher frequency of such reactions ${ }^{4}$ even if long term gold treatment is established. This combination should be avoided where possible.

- The clinical picture started to develop after only 2 hours of gold administration with just a $30 \mathrm{mg}$ cumulative gold dose. Most case reports have suggested higher cumulative dose exposure ${ }^{25}{ }^{6}$ and longer duration of treatment. To our knowledge such a florid onset has not been previously reported. 


\section{Authors' affiliations}

A Hafejee, M J Burke, Department of Rheumatology, Burnley General Hospital, Casterton Avenue, Burnley, Lancashire BB10 2PQ, UK

Correspondence to: Dr A Hafejee; abdulhafejee@hotmail.com

Accepted 2 December 2003

\section{REFERENCES}

1 Gordon DA, Klinkhoff AV. Gold compounds and penicillamine in the rheumatic diseases. In: Kelley W, Harris ED, Ruddy S, Sledge CD, eds.
Textbook of Rheumatology 5th ed. Philadelphia: WB Saunders, 1997:759-769.

2 Winterbauer RH, Wilske KR, Wheelis RF. Diffuse pulmonary injury associated with gold treatment. N Engl J Med 1976;294:919-921.

3 Tamioka H, King JE Jr. Gold induced pulmonary disease: clinical features, outcome and differentiation from rheumatoid lung disease. Am J Resp Crit Care Med 1997; 155:1011-1020.

4 Healey LA, Backes MB. Nitritoid reactions and angiotensin converting enzyme inhibitors (letter). N Engl J Med 1989;321:763.

5 Gould PW, McCormack PL, Palmer DG. Pulmonary damage associated with sodium aurothiomalate therapy. J Rheumatol 1977;4(3):252-260.

6 Sinha A, Silverstone EJ, O'Sullivan MM. Gold induced pneumonitis: computer tomography findings in a patient with rheumatoid arthritis. 2001;40:712-714.

\section{An unusual complication of appendicitis}

\section{S L Mackie, A Keat}

A 32 year old man presented with a 3 day history of fever, central abdominal pain, and frequent loose bowel motions without blood or mucus. The pain had recently shifted to his right iliac fossa. He had previously been well and he was receiving no regular drugs. On examination he was systemically well, but rebound tenderness was noted in the right iliac fossa, and $\mathrm{C}$ reactive protein $(\mathrm{CRP})$ was raised $(78 \mathrm{mg} / \mathrm{l}$, reference range $<10)$. A diagnosis of acute appendicitis was made and he underwent appendicectomy. Histology disclosed serosal congestion with a predominantly eosinophilic infiltrate in the mucosa and deeper layers.

Postoperatively the fever resolved, but the diarrhoea continued for several weeks. Two weeks later he developed a right knee effusion associated with raised inflammatory markers (CRP $37 \mathrm{mg} / \mathrm{l}$ ). Subsequently, the left knee and right elbow also swelled, with 1 hour of morning stiffness. Synovial fluid from the knee and blood cultures was sterile; the diarrhoea was mild and stool cultures were not performed. Treatment with non-steroidal anti-inflammatory drugs and sulfasalazine was started. The arthritis resolved over the next 3 months, with normalisation of inflammatory markers; at the last review the patient had stopped all treatment and was well.

Serological testing showed raised titres (1/1280) of antibodies to Yersinia enterocolitica $0: 3$ ( $\geqslant 1 / 160$ being considered significant), which remained at 1/640 3 months later.

On the basis of the clinical picture and serology a diagnosis of yersiniosis was made.

\section{DISCUSSION}

Reactive arthritis following enteric $Y$ enterocolitica infection is well described. ${ }^{1} Y$ enterocolitica and $Y$ pseudotuberculosis are also well known causes of mesenteric adenitis, ileocolitis, and appendicitis, ${ }^{2}$ but reports of reactive arthritis following $Y$ enterocolitica appendicitis are surprisingly rare. ${ }^{3}$

Pure cultures of $Y$ enterocolitica have occasionally been isolated from acutely inflamed appendices, suggesting a primary pathogenic role for this species. ${ }^{5}$ Serological evidence of acute infection by $Y$ enterocolitica was also reported in three of 90 patients with acute appendicitis; $;^{6}$ of these, two had postoperative diarrhoea. In another series ${ }^{7}$ evidence of $Y$ enterocolitica or $Y$ pseudotuberculosis was found by a polymerase chain reaction technique in 10 of 40 cases of granulomatous appendicitis but in none of 30 cases of non-granulomatous appendicitis.

An unexpected feature of this case was that granulomas were not seen on histology. The significance of the eosinophilia is uncertain, but in other respects the histology was typical of acute appendicitis. The association of appendicitis and yersinia induced reactive arthritis appears to be surprisingly unusual, despite the common occurrence of each condition individually. Nevertheless, it is clearly important for physicians to be aware that abdominal pain in patients with reactive arthritis may signify the potentially lethal complication of appendicitis, and for surgeons to be aware that appendicitis may be complicated by reactive arthritis.

\section{Authors' affiliations}

S L Mackie, A Keat, Arthritis Centre, Northwick Park Hospital, Harrow, Middlesex HA1 3UJ, UK

Correspondence to: Dr S L Mackie, Department of Rheumatology, Leeds General Infirmary, Leeds LS1 3EX, UK; sarah.mackie@doctors.org.uk

Accepted 19 December 2003

\section{REFERENCES}

1 Ahvonen P, Sievers K, Aho K. Arthritis associated with Yersinia enterocolitica infection. Acta Rheumatol Scand 1969;15:232-53.

2 Cover TL, Aber RC. Yersinia enterocolitica. N Engl J Med 1989;321:16-24.

3 Strom $\mathbf{H}$, Johansson $\mathrm{C}$. Appendicitis followed by reactive arthritis in an HLA B27-positive man after infection with Yersinia enterocolitica, diagnosed by serotype specific antibodies and antibodies to yersinia outer membrane proteins. Infection 1997;25:317-19.

4 Ahvonen P. Human yersiniosis in Finland. II. Clinical features. Ann Clin Res 1972;4:39-48

5 Jepsen OB, Korner B, Lauritsen KB, Hancke AB, Andersen L, Henrichsen S, et al. Yersinia enterocolitica infection in patients with acute surgical abdominal disease: a prospective study. Scand J Infect Dis 1976:8:189-94.

6 Attwood SEA, Cafferkey MT, West AB, Healy E, Mealy K, Buckley TF, et al. Yersinia infection and acute abdominal pain. Lancet 1987;i:529-33.

7 Lamps LW, Madhusudhan KT, Greenson JK, Pierce RH, Massoll NA, Chiles MC, et al. The role of Yersinia enterocolitica and Yersinia pseudotuberculosis in granulomatous appendicitis. Am J Surg Pathol 2001 ;25:508-15. 


\title{
Interferon alfa in protracted arthritis of familial Mediterranean fever: a robust alternative for synovectomy
}

\author{
K Üreten, M Çalgüneri, A Mesut Onat, L Özçakar, I Ertenli, S Kiraz
}

Ann Rheum Dis 2004;63:1527. doi: 10.1136/ard.2003.019471

A 17 year old girl was admitted to our rheumatology clinic with right knee pain and swelling for the past 3 months. A diagnosis of familial Mediterranean fever (FMF) had been made 8 years previously; she had recurrent attacks of fever, abdominal pain, and knee arthritis. She had been using colchicine $1.5 \mathrm{mg} /$ day regularly since then. Although her abdominal attacks and fever had subsided with colchicine treatment, recurrent mild knee attacks occurred almost every month. Two years ago she was found to have the homozygous M694V gene mutation for FMF. Three months ago, she was admitted to hospital owing to monarthritis in her right knee-but this time with a prolonged and severe episode. She was given antibiotics, and a suspected diagnosis of septic arthritis was made. As the cultures did not yield any bacterial growth and her symptoms persisted, she applied to our department.

A physical examination disclosed painful and limited movement, swelling and warmth in the right knee joint. Laboratory findings were as follows: erythrocyte sedimentation rate: $96 \mathrm{~mm} / \mathrm{lst} \mathrm{h}, \mathrm{C}$ reactive protein: $165 \mathrm{mg} / \mathrm{l}(0-8)$, fibrinogen: $8.5 \mathrm{~g} / \mathrm{l}$ (1.4-4.3). Protracted arthritis of FMF was diagnosed and the dose of colchicine was increased to $2 \mathrm{mg} /$ day. Ten days later, she was seen on a control visit with complaints of abdominal pain, diarrhoea, skin rash-probably due to colchicine-and persistent knee arthritis, which did not respond to colchicine treatment. Accordingly, interferon alfa 4.5 million IU (twice a week) was started and the colchicine dose was decreased to $1.5 \mathrm{mg} /$ day.

Thereafter, she has been followed up every 10 days for 3 months and her knee arthritis has disappeared and the laboratory measures have improved (table 1). She is still being routinely followed up and is completely normal with the above mentioned regimen of interferon alfa and colchicine together with a protocol of isometric quadriceps strengthening exercises.

\section{DISCUSSION}

Arthritis in FMF usually comprises acute attacks, with complete resolution within a few days or 2 weeks. It is more common in patients with the homozygous M694V gene mutation. Occasionally, the attacks are protracted, lasting for several months, and chronic joint disease has been estimated to contribute about $5-10 \%$ to the joint manifestations in FMF. $^{12}$ However, once degenerative or necrotic changes ensue, the recurrent attacks of arthritis are no longer punctuated by symptom-free intervals. Additionally, the irreversible morphological changes in the joints become non-responsive to colchicine, corticosteroids, or non-steroidal anti-inflammatory drug treatment. Although ruling out a coexisting chronic inflammatory arthritis should remain a prerequisite, ${ }^{3}$ surgery is usually warranted in such cases. ${ }^{1}{ }^{4}$ To the best of our knowledge, a medical treatment alternative
Table 1 The changes in the laboratory variables of the patient with interferon alfa treatment

\begin{tabular}{llll}
\hline Interferon treatment & $\begin{array}{l}\text { ESR } \\
\text { (mm/1 st h) }\end{array}$ & $\begin{array}{l}\text { CRP } \\
\text { (mg/l) }\end{array}$ & $\begin{array}{l}\text { Fibrinogen } \\
\text { (g/l) }\end{array}$ \\
\hline Immediately before & 61 & 106 & 8.8 \\
Two weeks after & 35 & 11 & 4.9 \\
Six weeks after & 30 & 4 & 4.8 \\
Twelve weeks after & 25 & 4 & 4.5 \\
\hline
\end{tabular}

for these patients that would make synovectomy unnecessary has not been reported. Only one report, by Tunca et al, has described favourable effects of interferon alfa on the abdominal attacks of seven patients with FMF. ${ }^{6}$ As recent studies have disclosed up regulation of the MEFV gene by interferon, ${ }^{7}$ the mechanism-which could not have been substantiated previously-has become evident. Thus, overall, we advocate the use of inteferon alfa as an adjunct for the treatment of colchicine resistant arthritis attacks in FMF.

\section{Authors' affiliations}

K Üreten, M Çalgüneri, A Mesut Onat, I Ertenli, S Kiraz, Hacettepe University Medical School, Department of Rheumatology, Ankara, Turkey

L Özçakar, Hacettepe University Medical School, Department of Physical Medicine and Rehabilitation, Ankara, Turkey

Correspondence to: Dr K Üreten, Kaynarca sokak 4/5 Abidinpașa, Ankara, Turkey; kemalureten@yahoo.com

Accepted 18 January 2004

\section{REFERENCES}

1 Younes M, Kahn M-F, Meyer O. Hip involvement in patients with familial Mediterranean fever. A review of ten cases. Joint Bone Spine 2002;69:560-5.

2 Ince E, Cakar N, Tekin M, Kendirli T, Ozkaya N, Akar N, et al. Arthritis in children with familial Mediterranean fever. Rheumatol Int 2002;21:213-17.

3 Garcia-Gonzalez A, Weisman MH. The arthritis of FMF. Semin Arthritis Rheum 1992;22:139-50.

4 Salai M, Zemmer D, Segal E, Corat A, Heyman Z, Davidson B, et al. Chronic massive knee effusion in familial Mediterranean fever. Semin Arthritis Rheum 1997;27:169-72.

5 Yalçınkaya F, Tekin M, Tümer N, Özkaya N. Protracted arthritis of familial Mediterranean fever (an unusual complication). Br J Rheumatol 1997;36:1228-30.

6 Tunca M, Tankurt E, Akbaylar Akpinar H, Akar S, Hızlı N, Gönen O. The efficacy of interferon alpha on colchicine-resistant familial Mediterranean fever attacks: a pilot study. Br J Rheumatol 1997;36:1005-8.

7 Centola M, Wood G, Frucht DM, Galon J, Aringer M, Farrell C, et al. The gene for familial Mediterranean fever, MEFV, is expressed in early leukocyte development and is regulated in response to inflammatory mediators. Blood 2000;95:3223-31. 


\section{Transient bone marrow oedema in a child}

\section{Kröger, P Arikoski, J Komulainen, R Seuri, H Kröger}

Ann Rheum Dis 2004;63:1528-1529. doi: 10.1136/ard.2003.018804

$\mathrm{T}$ ransient bone marrow oedema (TBMO) is an uncommon condition associated with joint and bone pain on activity. The most common localisation is the proximal femur, and it mainly affects only one bone. ${ }^{1}$ Reports of bone marrow oedema in children are scarce. ${ }^{2-4}$

\section{CASE REPORT}

An 8 year old boy was referred to hospital owing to difficulty in walking. He had started ski jumping 2 weeks earlier, but his history showed no injuries in the extremities. He complained of pain in the knees, ankles, and wrists. Mild fever and signs of upper respiratory tract infection were detected and reactive arthritis was suspected. Treatment with naproxen was started and he was discharged. Ultrasound investigation showed only slight symmetrical oedema in the ankle joints. Haemoglobin, white blood cell count, and thrombocytes were all within normal limits.

During the next 2 weeks, the pain was localised in both feet and the patient was hardly able to walk. Palpation and compression of both feet was very painful. An $x$ ray examination which was carried out 2 weeks after the first visit showed marked osteopenia in the tarsal area and in distal parts of the tibia and fibula (fig 1). A magnetic resonance imaging (MRI) scan was performed 4 weeks after the beginning of the symptoms showed marked bone marrow oedema (fig 1). Transient osteoporosis was suspected. Bone scintigraphy showed areas of hyperperfusion both in the feet and the hands. An MRI scan was subsequently obtained of the hands also, which also showed bone marrow oedema. Axial bone mineral density was measured by dual $x$ ray absorptiometry and was normal. Serum calcium, phosphate, parathyroid hormone, alkaline phosphatase (AP), and vitamin D metabolites were normal. However, bone markers were raised (table 1 ).

During follow up the pain became less intensive and after 3 months, the condition had resolved clinically, although an
MRI scan was still abnormal. MRI normalised in 8 months. However, serum osteocalcin values remained raised, suggesting increased bone remodelling (table 1).

\section{DISCUSSION}

There are no data on the incidence of TBMO in children. However, it seems to be a relatively rare cause of foot and ankle pain also in adults. ${ }^{5}$ In another study of 1123 patients referred for MRI imaging of the foot, 72 patients with oedema-like bone marrow abnormalities were registered. ${ }^{6}$

The aetiology of TBMO is unknown but it may be associated with local vascular disturbances, microtrauma, bone contusion, or altered biomechanics. ${ }^{67}$ The $x$ ray examination is usually either normal or shows localised osteoporosis, as in our case. However, osteoporosis is a rare finding in bone biopsies. ${ }^{8}$ Histological studies have suggested ischaemic origin. ${ }^{9}$

The definitive diagnosis of TBMO is made by MRI. Bone contusion and bone bruises normally manifest as focal areas of low signal intensity in $\mathrm{T}_{1}$ weighted images and increased signal intensity in $\mathrm{T}_{2}$ weighted images, whereas bone oedema shows diffuse changes of intensity. ${ }^{1}$ In our patient marked bone marrow oedema was seen in both feet and hands.

Because of the unknown aetiology of bone changes we measured biochemical markers of bone metabolism. Serum $\mathrm{AP}$ values were within the normal range but both osteocalcin and procollagen type I C-peptide were high and remained high, although the clinical condition was relieved. However, except for AP, interpretation of these results is difficult because there are no established normative data for bone markers in children. ${ }^{10}$

The treatment of TBMO is not well established. Core decompression and vasodilatator treatment with iloprost have been suggested. ${ }^{4}$ Conservative treatment aims at protecting bone from weight bearing, both to prevent collapse of the articular surface and provide relief from pain. In this

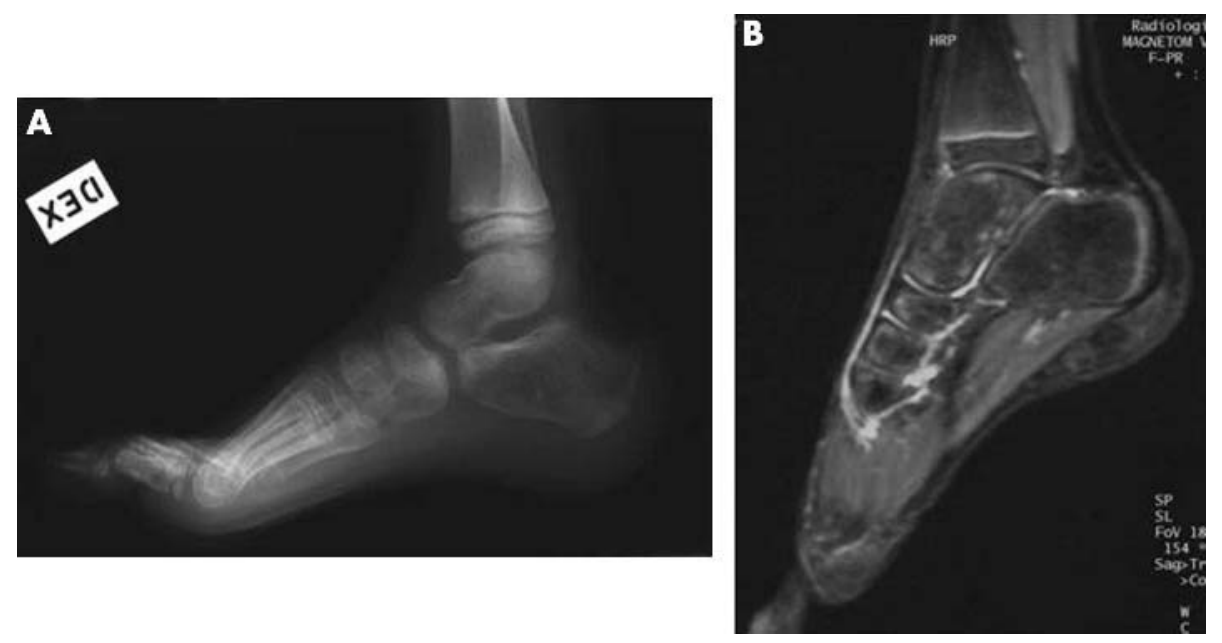

Figure 1 A radiograph showing marked osteoporosis in the tarsal and metatarsal bones. In the MRI scan, hyperintesity in the tarsal bones can be seen as a sign of oedema in $\mathrm{T}_{2}$ weighted images. 
Table 1 Laboratory data at baseline and during follow up

\begin{tabular}{|c|c|c|c|c|c|c|}
\hline & $\begin{array}{l}\operatorname{AP}(U / I) \\
(250-850)^{*}\end{array}$ & $\begin{array}{l}\mathrm{PICP}(\mu \mathrm{g} / \mathrm{I}) \\
(38-202)^{*}\end{array}$ & $\begin{array}{l}\text { ICTP }(\mu \mathrm{g} / \mathrm{l}) \\
(1.6-4.6)^{*}\end{array}$ & $\begin{array}{l}\mathrm{OC}(\mu \mathrm{g} / \mathrm{I}) \\
(1-11)^{*}\end{array}$ & $\begin{array}{l}\mathrm{Ca}(\mathrm{mmol} / \mathrm{l}) \\
(2.2-2.65)^{*}\end{array}$ & $\begin{array}{l}\mathrm{Pi}(\mathrm{mmol} / \mathrm{l}) \\
(1.2-1.8)^{*}\end{array}$ \\
\hline Baseline & 556 & & & & 2.42 & 1.46 \\
\hline 1 Month & 629 & 840 & 13 & 81.5 & & \\
\hline 8 Months & & 649 & 15.6 & 136.6 & & \\
\hline 12 Months & 640 & 726 & 13.8 & 112.7 & & \\
\hline
\end{tabular}

patient the use of anti-inflammatory drugs and rest relatively rapidly relieved pain, although changes in the MRI scan were seen for several months.

The aetiology of TBMO in our patient remains unknown: his history disclosed no trauma, but it is possible that ski jumping and hence either bone contusion or abnormal stress might have been the predisposing factors.

\section{Authors' affiliations \\ L Kröger, P Arikoski, J Komulainen, Department of Paediatrics, Kuopio University Hospital, FIN-70211 Kuopio, Finland \\ R Seuri, Department of Radiology, Kuopio University Hospital, FIN- \\ 70211 Kuopio, Finland \\ H Kröger, Department of Surgery, Kuopio University Hospital, FIN- \\ 70211 Kuopio, Finland \\ Correspondence to: Dr L Kröger; liisa.kroger@kuh.fi}

Accepted 18 January 2004

\section{REFERENCES}

1 Beltran J, Shankman S. MR imaging of bone lesions of the ankle and foot. MRI Clin North Am 2001;9:553-66.

2 Nicol RO, Williams PF, Hill DJ. Transient osteopaenia of the hip in children. J Pediatr Orthop 1984;4:590-2.

3 Pay NT, Singer WS, Bartley E. Hip pain in three children accompanied by transient abnormal findings on MR images. Radiology 1989;171:147-9.

4 Aigner J, Petje G, Schneider W, Krasny C, Grill F, Landsiedl F. Juvenile bonemarrow oedema of the acetabulum treated by iloprost. J Bone Joint SurgBr 2002;84:1050-2.

5 Radke S, Vispo-Seara J, Walther M, Ettl V, Eulert J. Transient bone marrow oedema of the foot. Int Orthop 2001;25:263-7.

6 Zanetti M, Steiner CL, Seifert B, Hodler J. Clinical outcome of edema-like bone marrow abnormalities of the foot. Radiology 2002;222:184-8.

7 Eustace S, Keogh C, Blake M, Ward RJ, Oderr PJ, Dimasi M. MR imaging of bone oedema: mechanisms and interpretation. Clin Radiol 2001;56:4-12.

8 Plenk HJ, Hofmann S, Eschberger J, Gstettner M, Kramer J, Schneider W, et al. Histomorphology and bone morphometry of the bone marrow edema syndrome of the hip. Clin Orthop 1997;334:73-84.

9 Wilson AJ, Murphy WA, Hardy DC, Totty WG. Transient osteoporosis: transient bone marrow edema. Radiology 1988;167:757-60.

10 Szulc P, Seeman E, Delmas P. Biochemical measurements of bone turnover in children and adolescents. Osteoporosis Int 2000;11:281-94.

\section{Joint lavage and pseudogout}

\section{P Pasquetti, E Selvi, K Righeschi, M Fabbroni, R De Stefano, E Frati, R Marcolongo}

J oint lavage, although its efficacy is still under debate, ${ }^{1-6}$ seems to be effective, mostly, in the treatment of gonarthritis associated or not with chondrocalcinosis (CC). ${ }^{237}$ Paradoxically, acute pseudogout is a complication of this technique. ${ }^{8}$ Our study aimed at evaluating the incidence of pseudogout in 73 patients with gonarthritis, associated or not with CC, who underwent arthroscopic lavage (AL).

\section{METHODS AND RESULTS}

In this retrospective study we assessed the incidence of pseudogout attacks that occurred 24 hours after surgery in 73 consecutive patients with gonarthritis (52 women (71\%), 21 men $(29 \%)$ ), who underwent AL of the knee at our hospital. All the patients had medium-severe symptomatic osteoarthritis, according to Kellgren and Lawrence's classification (II-III-IV degrees), ${ }^{9}$ and were unresponsive to drugs (that is non-steroidal anti-inflammatory drugs, analgesics, disease modifying osteoarthritis drugs) and rehabilitative treatment.

AL was carried out with an arthroscopic sheath $5.5 \mathrm{~mm}$ in diameter and $12 \mathrm{~cm}$ long, preceded by intra-articular carbocaine $2 \%$. Twenty three patients had radiological or laboratory signs of CC, including $x$ ray evidence of meniscal and cartilaginous opacities and/or birefringent positive intra- and extracellular calcium pyrophosphate crystals (CPPD) in the synovial fluid (group A). The remaining 50 patients had gonarthritis with no evidence of CC (group B) (table 1 ). They were followed up clinically $\mathrm{l}$ and 10 days after the AL.

The relative risk of the incidence of pseudogout in group A compared with group B patients was estimated from the analysis of contingency tables, by odds ratios (ORs); the $95 \%$ confidence interval $(95 \% \mathrm{CI})$ was also calculated. The differences between the two groups were studied by the $\chi^{2}$ and Fisher tests applied to a $2 \times 2$ contingency table. The association of age, sex, and radiographic osteoarthritis grade with pseudogout incidence after lavage was evaluated, respectively, by unpaired $t$ test, Fisher test, and $\chi^{2}$ test carried out on contingency tables. A value of $p<0.05$ was considered significant.

Of the 73 patients treated (mean (SD) age $59.4(6.7)$ ), nine (12\%) had an arthritic episode within 24 hours after surgery. In each of these cases, wet sinovianalysis confirmed the inflammatory nature of the phenomenon (leucocyte counts between $5 \times 10^{9}$ and $\left.30 \times 10^{9} / 1\right)$; polarising microscopy demonstrated the presence of CPPD. In all nine cases, culture and bacterioscopic examination of the synovial fluids were negative. The joint was injected with steroids, and the phenomenon resolved completely within 24 hours.

Six of the nine patients with pseudogout attack (26\%) belonged to group A, while three $(6 \%)$ belonged to group B. 


\begin{tabular}{|c|c|c|c|}
\hline & Group A & Group B & Total \\
\hline $\begin{array}{l}\text { Patients treated, No (\%) } \\
\text { Age, mean (SD) } \\
\text { Sex (F/M) } \\
\text { Pseudogout attacks, No (\%) }\end{array}$ & $\begin{array}{l}23(32) \\
60.4(4.2) \\
15 / 8 \\
6(26)^{*}\end{array}$ & $\begin{array}{l}50(68) \\
58.2(6.8) \\
37 / 13 \\
3(6)\end{array}$ & $\begin{array}{l}73 \\
59.4(6.7) \\
52 / 21 \\
9(12)\end{array}$ \\
\hline
\end{tabular}

The OR of group A compared with group B was estimated to be 5.5 (95\% CI 1.24 to $24.60 ; \mathrm{p}<0.05$ ) (table 1 ).

\section{DISCUSSION}

The results of this study underline the significant incidence (26\%) of pseudogout as a possible complication of AL in patients with CC (table I).

Among the pathogenic hypotheses, mechanical-traumatic is the most likely; in fact, the lavage fluid could promote "crystal shedding", due to the release of CPPD embedded in the joint tissues. ${ }^{8}$

Furthermore, it should be noted that this complication was also documented in three patients with gonarthritis without radiological or laboratory evidence of CC. This might be due to the fact that in a variable percentage of cases, microscopy for crystals in synovial fluid may yield false negative results. $^{310}$ According to our data the age, sex, and radiographic grade of the patients had no significant association with the incidence of pseudogout after lavage.

In conclusion, pseudogout should be considered as a possible complication of AL, mainly in patients with CC, with about a fivefold risk compared with patients with osteoarthritis.

\section{ACKNOWLEDGEMENTS}

We are grateful to Professor G Cevenini, Department of Surgery and Bioengeneering, University of Siena, for statistical assistance.

\section{Authors' affiliations}

P Pasquetti, E Selvi, K Righeschi, M Fabbroni, R De Stefano, E Frati, R Marcolongo, Section of Rheumatology, Department of Clinical Medicine and Immunological Science, University of Siena, Policlinico "Le Scotte", V le Bracci 53100, Siena, Italy

Correspondence to: Dr P Pasquetti; pasquetti3@virgilio.it

Accepted 7 February 2004

\section{REFERENCES}

1 Ike RW, Arnold WJ, Rothschild EW, Shaw HL, Tidal Irrigation Cooperating Group. Tidal irrigation versus conservative medical management in patients with osteoarthritis of knee: a prospective randomised study. J Rheumatol 1992;19:722-9.

2 Ayral X, Dougados M. Joint lavage. Rev Rhum Engl Ed 1995;62:281-7.

3 Ike RW. Joint lavage. In: Brandt KD, Doherty M, Lohmander LS, eds. Osteoarthritis. New York: Oxford University Press, 1998:359-377.

4 Hochberg MC, Altman RD, Brandt KD, Clark BM, Dieppe PA, Griffin MR, et al. Guidelines for the medical management of osteoarthritis. Part II: Osteoarthritis of knee. American College Rheumatology. Arthritis Rheum 1995;38:1541-6.

5 Moseley JB, O'Malley K, Petersen NJ, Menke TJ, Brody BA, Kuykendall DH, et al. A controlled trial of arthroscopic surgery for osteoarthritis of the knee. N Engl J Med 2002;11:81-8

6 Bradley JD, Heilman DK, Katz BP, Gsell P, Wallick JE, Brandt KD. Tidal irrigation as treatment for knee osteoarthritis: a sham-controlled, randomized, double-blinded evaluation. Arthritis Rheum 2002;46:100-8

7 O'Connor RL. The arthroscope in the management of crystal-induced synovitis of the knee. J Bone Joint Surg Am 1973;55:1443-9.

8 Bennett RM, Lehr JR, Mc Carty DJ. Crystal shedding and acute pseudogout. An hypothesis based on a therapeutic failure. Arthritis Rheum 1976;19:93-7.

9 Kellgren JH, Lawrence JS. Radiological assessment of osteoarthritis. Ann Rheum Dis 1957; 16:494-501.

10 Doherty M. Calcium pyrophosphate dehydrate. In: Klippel JH, Dieppe PA eds. Rheumatology. London: Mosby, 1998;8:16.1-12. 